\title{
Deep Problems in Shallow Lakes: Why Controlling Phosphorus Inputs May Not Restore Water Quality'
}

\author{
Karl Havens ${ }^{2}$
}

Florida's thousands of lakes are shallower than most people realize, and some unique properties of shallow lakes make them challenging to restore if they have been degraded by nutrients or other pollutants.

For many Florida lakes, improvement of water quality now is mandated by the federal Clean Water Act, because human activities have over-enriched their waters with nutrients. Two nutrients that most often pollute lakes are nitrogen and phosphorus. These occur naturally in the environment, including in lakes, and they are essential to the growth of aquatic life. However, when higher than natural levels occur due to human inputs, this can have undesired effects, such as blooms of toxic algae and reduced water clarity (Conley et al. 2009; Lewis et al. 2011).

The Clean Water Act requires that the input of nutrients (and other pollutants) does not impair fish and wildlife habitat, recreation activities such as swimming or fishing, or the water's drinkability. Reversing the symptoms of nutrient pollution, however, is a challenge in shallow lakes that are typical in Florida. Shallow lakes have natural dynamics that resist change, making it difficult to improve water quality even when inputs of nutrients are reduced (Havens and Schelske 2001).

This fact sheet examines how water managers track nutrients as they cycle through Florida's lakes. Most of the focus is on phosphorus, which is found mainly in soils and sediments. Because nitrogen cycles through the atmosphere as well as the land and sea, it involves many more microbiological processes, and a full examination is beyond the scope of this discussion.

\section{Calculating Nutrients with the Mass Balance Model}

To determine the amount of nutrient reduction needed to restore Florida's lakes and meet the Clean Water Act, water managers rely on mathematical equations called mass-balance models that act much like a checking account. Instead of money, they track amounts of nutrients and pollutants entering and exiting the water column of the lake.

The concept seems straightforward, but often a mass balance model must factor in a number of chemical and biological processes that take into account how Florida's shallow lakes will respond to changes in nutrient levels. Otherwise, water managers risk coming up with incorrect reduction targets that won't bring about desired improvements in water quality.

In its simplest form, the mass-balance model used to compute nutrient reduction is composed of three terms:

$$
M_{\text {in }}=M_{\text {out }}+M_{\text {sed }}
$$

In this case, $M_{\text {in }}$ is the amount, or mass, of nutrients entering the lake over a period of time. The term $\mathrm{M}_{\text {out }}$ is the mass leaving the lake. The term $\mathrm{M}_{\text {sed }}$ is the mass of nutrients that

1. This document is SGEF198, one of a series of the Florida Sea Grant College Program, Florida Cooperative Extension Service, Institute of Food and Agricultural Sciences, University of Florida. Original publication date January 2013. Visit the EDIS website at http://edis.ifas.ufl.edu.

2. Karl Havens, director, Florida Sea Grant College Program, Institute of Food and Agricultural Sciences, University of Florida, Gainesville, 32611. 
settle into the bottom sediments. Typically all of these terms are measured in units of tons per year, and to account for year-to-year variability in nutrient input, a mass balance is done for several successive years before an attempt is made to specify a nutrient loading reduction goal.

The terms in the mass-balance model are easily measured, except for $\mathrm{M}_{\text {sed, }}$ the amount of nutrients lost to the sediments. That quantity proves to be more difficult to measure precisely. One reason is because the rate that phosphorus in the lake's muddy bottom is released into the water is controlled by the amount of amount of oxygen in the water, and even the water's $\mathrm{pH}$. Water managers must therefore use more sophisticated mass-balance models to incorporate these kinds of chemical processes to better approximate $\mathrm{M}_{\text {sed }}$. Yet even these are sometimes too simple. The models must further account for biological processes that occur in shallow lakes, or managers risk setting nutrient reduction goals that are too high or too low to achieve the desired level of water quality improvement (Havens and Schelske 2001).

\section{Biological Challenges of Reducing Phosphorus in Lakes}

Phosphorus enters lake waters from natural and man-made sources in the surrounding watershed. Once there, many chemical and biological processes from the bottom to the top of the food web can affect how much phosphorus remains present in the water column, and the way a lake might respond to attempts to reduce the phosphorus load. (See figure below). In general, these same dynamics apply to nitrogen, but they are more complex and involve many more microbiological processes. We know however that controlling both phosphorus and nitrogen is essential to reversing symptoms of nutrient over-enrichment in Florida's lakes (Conley et al. 2009).

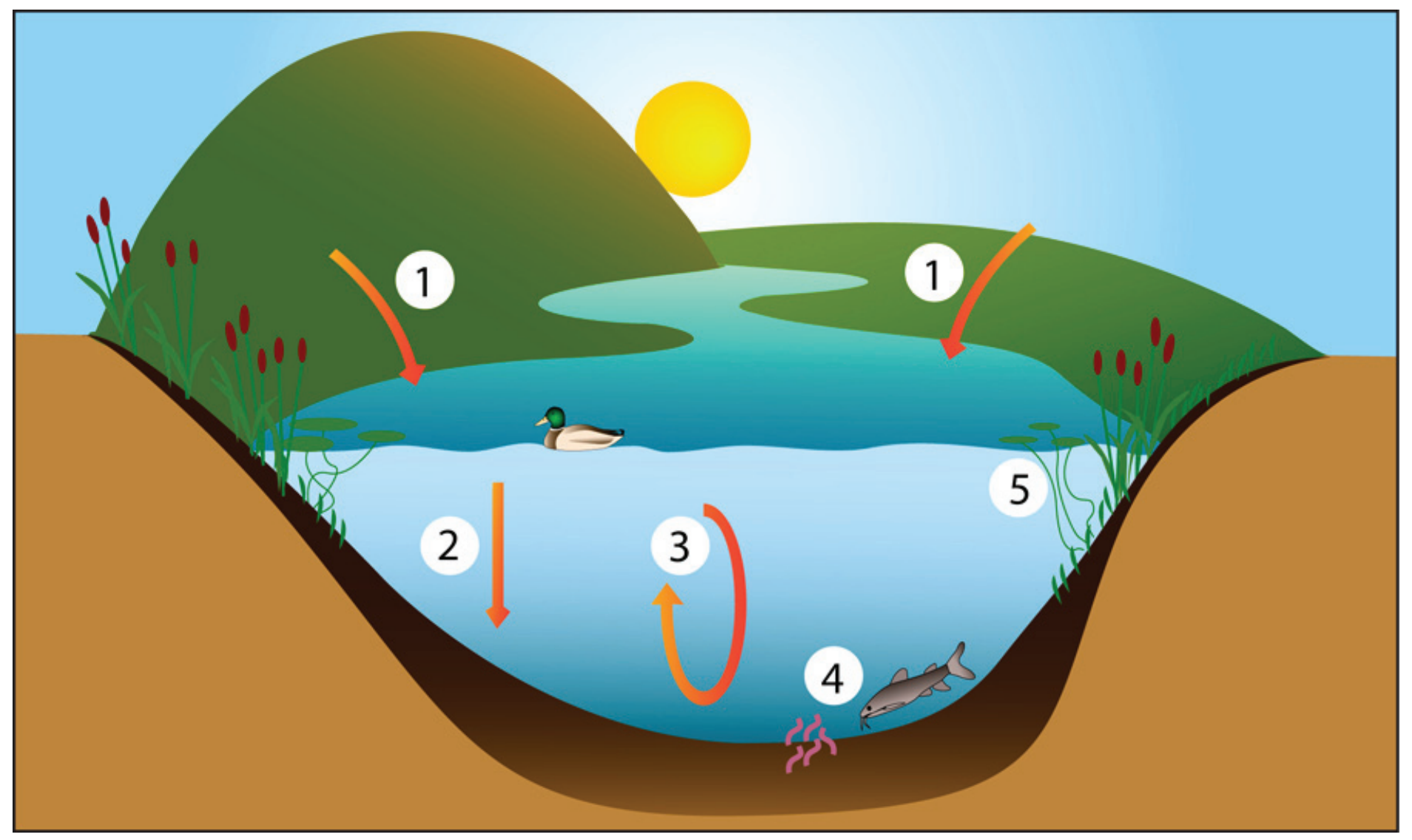

Figure 1. Many processes affect phosphorus levels in a shallow lake. (1) Phosphorus enters the lake from the surrounding watershed. (2) When living organisms in the lake die, they sink to the bottom, transporting phosphorus to the sediments and building up an internal phosphorus reserve. (3) Certain algae can regulate their buoyancy in the water column and travel down to the sediments to obtain phosphorus and then back up into the lighted area of the upper waters to grow and form blooms. (4) Bottom-dwelling worms and certain fish feed in the sediments and excrete phosphorus back into the water, where it can be used by algae. (5) Healthy, submerged plants perform a variety of functions that reduce amounts of phosphorus in the water. [click on photo to enlarge]

Credits: Illustration by Chris Jones, Florida Sea Grant. 


\section{Persistent Response by Nuisance Algae}

The water column of a lake is populated by a variety of microscopic organisms including bacteria, algae and small animals called zooplankton that feed on algae and are eaten by fish. As phosphorus is added to lakes, algae become more abundant and tend to change from small types, such as diatoms and green algae that are easily grazed by zooplankton, to large types of blue-green algae that resist grazing and form dense and sometimes noxious blooms. Whereas lakes that are deficient in phosphorus can respond rapidly to a reduction in phosphorus inputs, the blue-green algae in phosphorus-enriched lakes may not behave in this manner. After a prolonged period of excessive phosphorus inputs, there may be more phosphorus in the water than the algae can use. When this happens, reducing the external inputs of phosphorus to the lake will have no noticeable effect on the amount of algae and occurrence of blooms until that surplus phosphorus is depleted. In lakes where the surplus is large, this could take years.

Certain blue-green algae that are common in phosphorusenriched lakes, including a common Florida genus called Microcystis, have the ability to regulate their buoyancy, much like a diver. These algae migrate down to the bottom sediments where phosphorus has accumulated over time from settling of dead material including bacteria, algae and zooplankton, and detritus from outside the lake. While at the bottom, the algae can become saturated with phosphorus and then return to the lighted surface water and form blooms. When programs are implemented to reduce phosphorus in the water column, these algae can continue to use the sediments as a phosphorus source. The process can continue for years in lakes with large quantities of sediment phosphorus, long after external inputs have been reduced.

\section{Submerged Plants' Role in a Recovery}

Most lakes in Florida are shallow, just a few feet deep, and they can exist in two states - clear water with aquatic plants, or turbid water with suspended algae. As lakes undergo phosphorus enrichment, they can reach a point where they switch from clear to turbid. There is some controversy about whether this switch happens abruptly when a threshold level of phosphorus is reached (Scheffer et al. 1993) or gradually over many years (James et al. 2005). Yet there is no debate that when a lake switches to a turbid state, the dense algae in the water shade out the submerged plants. When plants die, they cannot provide benefits that reduce the impacts of phosphorus. They can no longer stabilize sediments with their roots, support attached algae which take up phosphorus from the water, or provide daytime cover for zooplankton which emerge at night to feed on suspended algae.

When lakes lose the benefits provided by plants, they experience a greater level of water quality degradation for any given level of phosphorus. Lakes that have lost their plants thus require a greater reduction of phosphorus to switch back to clear water than they would need if plants were still there doing beneficial things. As an example, a phosphorus concentration of 100 parts per billion (ppb) might switch a clear, plant-dominated lake into a turbid, algal-dominated lake. However, when the plants and their benefits are gone, lake managers may need to reduce phosphorus to $80 \mathrm{ppb}$ or lower to switch it back. This has implications for setting an appropriate phosphorus reduction goal. In the absence of plants, recovery may not occur unless phosphorus inputs are reduced below measured historical levels when good water quality occurred.

\section{Worms, Fish and Lake Recovery}

When organisms in the lake die, they sink to the bottom and decay, releasing phosphorus to the sediments through bacterial composition. If there are no living organisms in the sediments to receive inputs of phosphorus, over time, the sediments become phosphorus-enriched. When inputs of phosphorus are reduced, the older, enriched sediments will become buried beneath newer sediments that are less enriched, and the lake will recover. Unless something happens to mix the sediments, this natural burial process should protect the lake from a recurrence of excessive phosphorus.

Sometimes a disruptive event such as a hurricane or tropical storm can stir up buried, phosphorus-rich sediments in a shallow lake and restart phosphorus enrichment and the associated negative consequences, as happened recently in Lake Okeechobee (Havens, Beaver, Casamatta et al. 2011).

More often, however, living organisms in the sediments or feeding at the sediment surface inhibit the recovery of lakes by continually stirring up the phosphorus-rich sediments and preventing them from becoming buried. In nutrient-enriched lakes it is common to find high densities of worms called oligochaetes in the bottom sediments. Oligochaetes feed on dead material, with their heads buried in the sediment and their posterior ends sticking out into the water. They constantly excrete phosphorus back into the water column, like tiny biological pumps moving phosphorus from a burial site at the bottom of the lake back to the water, where it is available to algae. 
In a similar way, nutrient-enriched lakes often support high densities of bottom-feeding fish such as shad and catfish. These fish physically disturb the sediments, and they feed and excrete phosphorus just like the worms. Taken together, the worms and fish can provide a long-term supply of phosphorus that is not accounted for in most mass-balance models used to determine nutrient load reductions. When worms or bottom-feeding fish are present, water managers may attain their phosphorus-reduction goal, but find that the lake will not recover until additional measures are taken. Those might include removing bottom-feeding fish, dredging to remove mud sediment, or chemically treating the sediment to kill the worms. These measures are costly and sometimes do not work. Before they are attempted, studies are required to determine the likely cost and benefits. In some cases, it may not be feasible to move forward with in-lake rehabilitation measures.

\section{Weighing the Cost and Benefits}

Models used to establish reductions in phosphorus inputs to lakes routinely take into consideration mass balances of phosphorus, and may even include chemical processes that are known to happen at the sediment-water interface. Rarely do models consider the various biological processes described here, though these can be particularly important in shallow lakes, which are the most common kind in Florida and in many low-lying areas of the world. This means that phosphorus reduction goals may often be incorrectly specified, and that managers might consider a multi-pronged, repetitive approach suggested by Havens and Schelske (2001). In that approach the phosphorus reduction goal is periodically revisited and adjusted in order to consider new science, and to better meet the desired end point for a lake's rehabilitation. In certain cases, it may be determined that it is too costly or impractical to rehabilitate a shallow, phosphorus-enriched lake if the lake has experienced many years of excessive phosphorus inputs and has an array of biological processes that will resist recovery.

\section{References}

Conley, D.J., H.W. Paerl, R.W. Howarth, D.F. Boesch, S.P.

Seitzinger, K.E. Havens, C. Lancelot, and G.E. Likens. 2009.

Controlling eutrophication: nitrogen and phosphorus.

Science 323: 1014-1015.

Havens, K.E., J.R. Beaver, D.A. Casamatta, T.L. East, R.T. James, P. McCormick, E.J. Phlips and A.J. Rodusky. 2011. Hurricane effects on the planktonic food web of a large subtropical lake. Journal of Plankton Research 33: 1081-1094.

Havens, K.E. and C.L. Schelske. 2001. The importance of considering biological processes when setting total maximum daily loads (TMDL) for phosphorus in shallow lakes and reservoirs. Environmental Pollution 113: 1-9.

James, C., J. Fisher, V. Russel, S. Collings and B. Moss. 2005. Nitrate availability and hydrophyte species richness in shallow lakes. Freshwater Biology 50: 1059-1063.

Lewis, W.M., Jr., W.A. Wurtsbaugh and H.W. Paerl. 2011. Rationale for control of anthropogenic nitrogen and phosphorus to reduce eutrophication of inland waters. Environmental Science and Technology 45: 300-305.

Scheffer M., S.H. Hosper, M.L. Meijer, B. Moss and E. Jeppesen. 1993. Alternative equilibria in shallow lakes. Trends in Evolution and Ecology 8: 275-279

\section{Additional Reading}

Effects of Climate Change on the Eutrophication of Lakes and Estuaries http://edis.ifas.ufl.edu/sg127

Rethinking the Role of Nitrogen and Phosphorus in the Eutrophication of Aquatic Ecosystems http://edis.ifas.ufl.edu/sg118 